the days of the week down one side and four columns alongside so that the appropriate square could be ticked when the dose was taken. This would provide patient and doctor with a handy visual check on drug compliance. On the back of the card could be printed details of any important side effects or contraindications.

\section{Michael KLABER} London Hospital, London E1

\section{Preventing infective endocarditis}

SIR,-Your leading article (17 December, $p$ 1564 ) is useful in drawing attention to the American Heart Association's latest recommendations ${ }^{1}$ on this important subject. It is perhaps regrettable that in Britain we have not managed to publish a similar report. ${ }^{2}$ Such a report was, in fact, prepared in mid-1975 and, largely owing to entrenched opinions, has not yet seen the light of day. In the preparation of this report I was in close communication with the American team, and the recommendations arrived at were virtually identical. I would, therefore, commend a study of the American Heart Association's full text to your readers.

Parenteral prophylaxis should be given in all patients with prosthetic valves and those treated in hospital. Your article mentions that the indications for an oral regimen are not clear. These were dealt with in my letter to the $B M Y$ in $1975^{2}$ and, in brief, arise from the fact that in this country in general dental practice, oral regimens are already widely used, that dentists will not give intramuscular injections to their patients, and liaison with the patient's doctor to permit injection to be given at the appropriate time is simply not practicable. Furthermore, the work of Pelletier et al suggests that a suitable oral regimen is efficiently bactericidal.

Because of the number of cases of infective endocarditis that do not follow a recognisable insult the importance of good conservative dental care cannot be too frequently stressed.

The suggestion in your final paragraph that "a modified technique might either confirm or qualify the conclusions drawn and possibly render the clinician's task less burdensome" seems to me to perpetuate the heavy weather that is made of this subject. Surely we have admirable recommendations before us and we should follow them until better are produced. In the light of present evidence they are "as harmless as possible, and as effective as possible."4

Hugh A Fleming

Addenbrooke's Hospital

Cambridge

${ }^{1}$ American Heart Association, Circulation, 1977, 56,

139A.
2 Fleming, H A, British Medical fournal, 1975, 2, 541. Pelletier, L L, Durack, D T, and Petersdorf, R G,

fournal of Clinical Investigation,

\section{Skateboard injuries}

SIR,-I was interested to note the distribution of injuries following skateboard accidents in Dr Cynthia Illingworth's article (24-31 December, p 1636).

Of particular note was the discovery of six fractures of the scaphoid out of 37 patients radiographed. Fractures of the scaphoid in children are very rare and if the incidence of scaphoid fractures in this small series is borne out by larger series it would seem extremely important for this to be brought to the notice of other people seeing skateboard injuries.

D W PILling

Sheffield

\section{Anorexia nervosa and family therapy}

SIR,-Your leading article on anorexia nervosa (7 January, p 5) gives fair mention of the importance of family factors. Many family therapists would want to emphasise the value of considering the family system-the "whole" which is more than the sum of the parts-and the significance of the blurring of the intergenerational boundary.

A family with an inadequate boundary between parents and children may present with symptomatology other than anorexia nervosa, but often where this condition is present the boundary problem seems to be especially relevant and striking. Therapy may be directed towards a strengthening of marita bonds and to a lessening of the emotional overinvolvement between child and parents. ${ }^{1}$

\section{Child Guidance Centre,}

Coventry

JAMES WARNER

Minuchin, S, Families and Family Therapy. London, Tavistock Publications, 1974.

\section{Cough in farmer's lung disease}

SIR,-Cough is an important diagnostic feature of farmer's lung disease (FLD). ${ }^{1}$ In most accounts, however, it is not stated whether the cough is dry or whether a significant amount of sputum is produced. Parratt et $a l^{2}$ and Grant et $a l,{ }^{3}$ for instance, use the dry cough as one criterion to select their cases of FLD. We think that the productivity of the cough is an important clinical element in the disease.

We have cultured specimens of sputum for the organisms associated with FLD since $1969^{4}$; the appearance (purulence, etc) of the sputum was also noted. From 1969 to 1977 80 isolations of Micropolyspora faeni and 25 isolations of Thermoactinomyces spp (mainly $T$ candidus $^{5}$ were made. Patients from whom these isolations were made all had clinical FLD; 35 patients $(50 \%)$ had copious sputum which was frequently purulent. Some of our patients appear to have had FLD for many years although they have avoided contact with mouldy hay. One patient has given up his farm and been a bus driver for the past two years but still produces positive sputum cultures.

We suggest that FLD can manifest itself in two ways, each with its symptomatology and serology. Firstly, FLD can appear as a mild acute illness, with symptoms which include a dry cough, that appears some hours after exposure to mouldy hay. The patients are serologically negative or weakly positive and thermoactinomycetes are not isolated from the sputum. But FLD can also appear insidiously as a chronic disabling disease with profuse purulent sputum and strongly positive serological findings; thermoactinomycetes can readily be isolated from the sputum. We suggest that the first manifestation of FLD is a "primary" sensitivity response and the latter disease process is the product of actual colonisation of the lung by thermoactinomycetes. Plate tests indicate tetracycline sensitivity of the thermoactinomycetes under study and it would seem to be logical to treat the chronic disease with tetracycline.

F BRIAN GREATOREX JOHN PETHER

Public Health Laboratory, Taunton and Somerset Hospital,

'Campbell, J M, British Medical fournal, 1932, 2, 1143 Parratt, D, et al, Clinical and Experimental Immunology,

Grant, I W B, et al, British Medical fournal, 1972, 1,

Pether, J V S, and Greatorex, F B, British fournal of Greatorex, F B, and Pether, JV S, Lancet, 1976, 1,
1134 .

\section{Campylobacter enteritis in Sweden}

SIR,-We read Dr M B Skirrow's report (2 July, p 9) with great interest and have adopted his technique for isolating campylobacteria from faeces. Between 15 July and 31 October we have isolated Campylobacter jejuni from 15 subjects (13 patients with diarrhoea and two healthy carriers). We can fully confirm previous observations on the severity of the diarrhoea in many cases-four of our patients had bloody stools. Agglutinating antibodies against formalinised suspensions of patients' strains have appeared in most cases.

Most of our patients (eight out of 13) have obviously been infected abroad (Finland, Spain, Great Britain, Tanzania) and in one case we have isolated $C$ jejuni from two members of the same family and also from the family dog, which also had an enteritis.

During the $3 \frac{1}{2}$ months 17 new cases of salmonellosis, five cases of shigellosis, and six cases of yersiniosis were diagnosed in our laboratory. Campylobacter thus seems to be as common a cause of diarrhoea in Sweden as any of the "established" pathogenic bacteria.

B LINDQUIST

J KJELLANDER T KOSUNEN

Departments of Clinical

Bacteriology and Paediatrics,

Regionsjukhuset,

Orrebro, Sweden

\section{Hair in the theatre}

SIR,-I was delighted to read $\operatorname{Dr} N$ A Simmons's letter on the flowing locks of the modern surgeon (14 January, p 111). To those of us old enough to remember the cropped heads of George Perkins and Philip Mitchiner these modern styles confirm what I have long suspected-that the Arbuthnot Lane technique of the '20s and ' 30 s which reduced sepsis in clean wounds to less than $1 \%$ has now been lost in an antibiotic euphoria. Recently I heard at a lecture one of the younger surgeons admitting to a sepsis rate of $8 \%$ in clean appendix wounds, and from talks with general practitioners who deal with patients discharged from hospitals there appears to be a real feeling of increasing sepsis in clean surgical wounds.

The surgeon's hair, of course, is probably only a minor factor in the problem, but if Dr Simmons's letter marks only the beginning 
of a return to Lane's technique and less reliance on antibiotics to cover simple lack of cleanliness in the theatres it will have done some good. If not I may feel safer, when my time comes, to have my prostate removed in the clean kitchen of my own home by a baldheaded surgeon. And that, sir, is not meant as a joke.

ROBERT BEWICK

Burton-on-Trent, Staffs

\section{Inheritance of Marfan's syndrome}

SIR,-Further to Dr J Burn's letter on the above subject (14 January, p 108) I should like to confirm the absence of mental handicap in Marfan's syndrome. I see the majority of the freshmen who come to this university each year, and over the past 15 years the incidence of this syndrome has been about 1 in 1500 The incidence in the general population is 1 in 20000 . QED.

Medical Centre,

University of Warwick,

Coventry

\section{Smoking and asthma}

SIR,-Dr F E de W Cayley (14 January, p $110)$ points out that giving up smoking may trigger the new appearance of type 1 hypersensitivity, and asks if we should encourage our asthmatic patients to smoke. It is true in our experience that type 1 hypersensitivity and cigarette smoking virtually exclude each other (though there may not be a direct causal link) and we frequently meet patients who had never had asthma until they stopped smoking.

We must not, however, advise our asthmatics to smoke since $(a)$ given the choice on would rather have asthma than cancer and coronary disease, and (b) patients who become asthmatic on stopping smoking might not have developed allergic disease if they had never started smoking in the first place. One could easily postulate that the chronic immunosuppression of smoking ${ }^{1}$ causes allergic sensitisation that only becomes manifest once the immunosuppression is removed.

\section{DAVID FREED}

\section{Department of Bacteriology and Virology,
University of Manchester}

Thomas, W, Holt, P G, and Keast, D, Nature, 1973,
243, 240.

\section{Carcinoma of the pancreas}

SIR,-In your recent leading article on this subject (10 December, p 1497) no mention is made of the important problem of differentiating carcinoma from pancreatitis, which may often be extremely difficult and may delay the diagnosis of cancer.

We have shown that the estimation of lactoferrin, an iron-containing glycoprotein, by radioimmunoassay in pure pancreatic juice obtained endoscopically is a sensitive and apparently specific method for the differentiation of these two conditions. ${ }^{1}$ We have now studied 20 patients with chronic pancreatitis, 10 patients with carcinoma of the pancreas, and 16 control subjects being investigated for suspected pancreatic disease and later found to be normal. The median lactoferrin concentration in control subjects was $83 \mu \mathrm{g} / \mathrm{l}$ (range 16-390); in patients with chronic pancreatitis $2240 \mu \mathrm{g} / 1$ (range 870-11 400); and in patient with pancreatic cancer $105 \mu \mathrm{g} / 1$ (range 10-387) In a single patient with both cancer and pancreatitis the lactoferrin level was $1300 \mu \mathrm{g} / 1$ However, the combination of cancer and pancreatitis is rare. ${ }^{2}$

These results suggest that the measuremen of lactoferrin in pure pancreatic juice may be useful diagnostic aid in pancreatic disorders, particularly the differentiation between chronic pancreatitis and pancreatic cancer.

S S FEDAIL

RichaRd HaRvey

PAUL R SALMON

A E READ

University Department of

Medicine,
Bristol Royal Infirmary,

Bristol

' Fedail, S S, et al, Gut, 1977, 18, A975.

Robinson, A, Scott, J, and Rosenfeld, D D, Radiology, 1970, 94, 289 .

\section{Vitamin D status in different subgroups} of British Asians

SIR,-Dollery et $a l^{1}$ suggested that the higher serum 25-hydroxycholecalciferol (25-OHD 3 ) concentrations of Goan Asians reported by Hunt et $a l^{2}$ might result from induction of hepatic mirrosomes by meat and fish found in the diet of this community but absent from that of the groups with lower serum 25-OHD values. Hunt et $a^{3}$ subsequently reported significant correlation between the serum $25-\mathrm{OHD}_{3}$ concentrations of the Asians originally surveyed and the percentage of protein derived from animal sources in the diet.

We decided to investigate in rats whether mea itself affects vitamin D metabolism. Three experiments were performed; in each of them groups of rats were given a meat or a vegetarian diet. In the meat diet the major protein source was boiled mutton; in the vegetarian diet it was wheat flour and cooked chickpeas. Apart from protein source the diets were designed to have similar percentage of energy from fat $(34 \%)$, protein $(12 \%)$, and carbohydrate $(54 \%)$, polyunsaturated :saturated ratios, and fibre content. In composition they resembled the meat and vegetarian diets of the Ugandan Asians originally surveyed. ${ }^{4}$

In the first experiment two groups of 16 vitamin $D$-depleted rats fed on one of the two diets were injected subcutaneously with $25 \mu \mathrm{g}$ of vitamin $\mathrm{D}_{3}$ Three weeks later 10 rats were killed and thei serum assayed for 25-OHD. For the second experiment two groups of 10 matched pairs of rats similarly depleted and fed were injected with $25 \mu \mathrm{g}$ of $4-{ }^{14} \mathrm{C}$-cholecalciferol. Faeces were collected over five weeks and three-day collections were combusted and analysed for ${ }^{14} \mathrm{C}$ content. The third experiment measured the rate of metabolism of drugs ("sleeping time") in rats fed the two diets. Sodium pentobarbitone and zoxazolamine were successively used since the enzymes involved in their metabolism show different responses to inducers. ${ }^{5}$

There was no significant difference between the serum $25-\mathrm{OHD}_{3}$ and faecal ${ }^{14} \mathrm{C}$ excretion in rats fed the meat and vegetarian diets. Neither was there any significant difference in the sleeping time of rats on each diet after administration of the drugs.

Miranda and $\mathrm{Webb}^{6}$ reported that large differences in the level and quality of protein in the diet affect the toxicity of heptachlor in rats; however these variables were minimised in our study. Fraser et $a l^{7}$ presented evidence in humans that antipyrine half life is $50 \%$ shorter in meat eaters than in vegetarians. They have also suggested ${ }^{1}$ a specific induction of hepatic vitamin D-25-hydroxylase by meat rather than a general induction of metabolic enzymes similar to that thought to occur in osteomalacia induced by anticonvulsants. Our experiments did not confirm these suggestions, however. We found no evidence for induction of hepatic vitamin D-25hydroxylase or increased metabolism and excretion of vitamin $D$ when feeding meat. Neither was the rate of drug metabolism increased on the meat diet.

C Elizabeth Neat A H NASH

SANDRA P HUNT

A S TRUSWELL

Nutrition Department,

Loendon W8

Dollery, C T, et al, British Medical fournal, 1977, 1 ,

104.

${ }^{3}$ Hunt, S P, et al, British Medical fournal, 1977, 1, 641. Hunt, S P, et al, PhD thesis, University of London, 1977.

Conney, A H, et al, fournal of Pharmacology and Experimental Therapeutics, 1960, 130, 1.

Miranda, C L, and Webb, R E, Food and Cosmetics Toxicology, 1973, 11, 63 . Fraser, H S, et al, Clinical Pharmacology and Thera-
peutics. In press.

Fibrinolytic inhibitors for acute gastric haemorrhage

SIR,-I welcome your timely leading article (17 December, p 1565) on the use of fibrinolytic inhibitors in the treatment of acute gastric haemorrhage. It may be of interest to readers to know that this study of gastric bleeding, started in Manchester in the mid-'60s, was a clinical one. Previous to our publication the stomach had not been suspected as a site of fibrinolysis and the investigation antedated the modern discoveries of the production of vascular activator.

This clinical problem concerned the operative treatment of patients suffering from uncontrollable gastric haemorrhage in whom no ulcer was detectable before and after opening the stomach. A rather high partial gastrectomy was the routine procedure in these patients. I had for many years examined the removed portion of the stomach in the theatre when the specimen was fresh in order to try to identify gastric erosions. The mucosal surface was washed, dried with blotting paper, and carefully scanned with a magnifying glass. This procedure was not helpful. In the majority of cases no abnormality was found; in a few cases a suspicious area was found and marked by transfixion with thread, but in only one did the pathologist confirm the presence of an erosion.

The conclusion I drew from these observations was that a stomach could feel and look normal, at operation, from the outside and inside and yet be harbouring a potentially lethal haemorrhagic lesion-presumably multiple. The surgeon who has just completed a partial gastrectomy and finds what looks like a normal mucosa and no ulcer in the removed stomach is likely to be disappointed. On the other hand the surgeon may consider his operation to have been well judged if he finds a definite superficial ulcer. This is sometimes present high on the lesser curve. There appeared to be a degree of physiological confusion here because it is the normal-looking gastric mucosa which is killing the patient 